\title{
RESEARCH IN FIBROUS PLANT PREPARATION FOR PRESSED SOLID BIOFUEL AND DETERMINATION OF PELLET INDICATORS
}

\author{
Dionizas Streikus $^{1}$, Algirdas Jasinskas ${ }^{1}$, Vytautas Kucinskas ${ }^{1}$, Jiri Masek ${ }^{2}$ \\ ${ }^{1}$ Aleksandras Stulginskis University, Lithuania; ${ }^{2}$ Czech University of Life Sciences Prague \\ dionizasstreikus@gmail.com, algirdas.jasinskas@asu.lt
}

\begin{abstract}
In the development of economical and convenient renewable energy fuel in the last years, pelleting of biomass has become the most used technology for biomass processing. Fibrous plants were chosen for biofuel production - fibrous hemp (Cannabis sativa L.) and fibrous nettle (Urtica dioica L.) - for their high productivity and soil undemanding. Three sorts of fibrous hemp were chosen: Felina 32, USO 31, Finola and one sort of fibrous nettle. Laboratory trials with plant preparation and usage for energy purposes were carried out in the Aleksandras Stulginskis University and Lithuanian Energy Institute. Biometric features of plant stems were determined, and, later, the plants were chopped, milled and granulated into pellets of $6 \mathrm{~mm}$ diameter. For chaff milling a hummer mill Retsch SM 200 was used, and the mill fractional composition was determined. Mill was granulated by a small capacity granulator with a horizontal matrix. The pellet quality indicators - moisture content, density, and strength and heat value were determined. The fibre plant pellet moisture content ranged from $7.3 \%$ to $10.0 \%$ and pellet density reached $899.3-1221.6 \mathrm{~kg} \cdot \mathrm{m}^{-3} \mathrm{DM}$ (dry matter). The strength of pellets was determined using the test equipment INSTRON 5960. Fibrous hemp USO 31 had the biggest strength (pressing force of pellet degradation) - 1223.21 N, Felina $32-1053.39 \mathrm{~N}$, Finola $-854.19 \mathrm{~N}$ and fibrous nettle pellets $-1345.94 \mathrm{~N}$. The heat value of the fibrous plant pellets varied from $17.1 \mathrm{MJ} \cdot \mathrm{kg}^{-1}$ to $17.6 \mathrm{MJ} \cdot \mathrm{kg}^{-1}$.
\end{abstract}

Keywords: fibrous plants, pressed biofuel, pellets, physical properties, density, strength, heat value.

\section{Introduction}

Plant biomass needs a more wide analysis in Lithuania, but it may be stated that it is a perspective fuel sort. It will decrease import of oil and other fossil fuel products to Lithuania. More attention would be paid to agriculture and farmers, plant biomass would be an income source. Nowadays, land for agriculture is wasted, and it can be used for various sorts of energy planting. Biofuel is the cheapest fuel sort and it can be used for electricity and heat production. In Lithuania, about $60 \%$ of heat energy is received from plant biomass and just $7 \%$ for electricity.

Fibrous plants could be used not only for fiber, building and other material production for domestic and industrial use, but it could also be a good raw material for biofuel production. Fibrous hemp and fibrous nettle stems consist of $75 \%$ chaff and $25 \%$ fibre, briquettes and pellets may be produced from these materials (before pressing, plants should be chopped). In Lithuania, there is a big potential of straw, but the use of straw for burning is problematic since straw has low ash melting temperature and big amount of chlorine. So, when burning, it forms slag, which accumulates on heat transfer equipment surfaces [1;2]. Hemp could be a perspective energy plant because its dry mass yield from hectare exceeds 15 tons; approximately, it is twice more than villow grown for fuel [3].

Hemp grows well in endowed with moisture and fertilized soils. It also grows well in drained peat bogs, as long as soil is not too much acidic. Non-conductive wet clay is not suitable for hemp. Cannabis is not demanding with regard to climatic conditions. However, these plants grow better in milder and wetter climate. Long-term droughts, especially during the flowering season of cannabis, could cause serious harm. Hemp has a deep, sometimes deeper than $2 \mathrm{~m}$, penetrating main root; the branches are growing off this root. The entire root system is usually set out in the $20-40 \mathrm{~cm}$ deep layer of soil. In the peat bogs, roots of hemp grow deeper from 30 to $80 \mathrm{~cm}$. Since ancient times, hemp has been grown in Lithuania for fiber, medicines and food [3].

The incandescent properties of cannabis are equivalent to timber of oak; its combustion products do not pollute the environment [4]. Cannabis is classified as the most productive bio-energy plant; if compared to others, their stems accumulate mainly fiber. These plants, depending on the characteristics of the variety and soil fertility conditions, typically produce from $8-10 \mathrm{t} \cdot \mathrm{ha}^{-1}$ to 13-17 $\mathrm{t} \cdot \mathrm{ha}^{-1}$, and sometimes even up to $25 \mathrm{t} \cdot \mathrm{ha}^{-1}$ biomass [3; 4].

Based on the research conducted in flax breeding, it can be stated that cannabis is very promising as a biofuel feedstock [5]. Moreover, if compared to other biomass suitable for burning agricultural plant waste (canola, wheat straw, etc.), combustion releases maximum amount of energy (18.5 MJ) and leaves at least $1.2 \%$ of ash. After cannabis cultivation soil is not exhausted; moreover, it is even 
enriched by returning nutrients taken from leaves and roots. Therefore, these plants are irreplaceable in the crop rotations. Also, they have absorption properties of heavy metals, so hemp is capable of returning polluted abandoned fields of agriculture [6].

Various literature sources present different data on cannabis need for moisture, but it is always mentioned that they need at least $250 \mathrm{~mm}$ of rainfall during the growing season. Some scientists argue that $300-400 \mathrm{~mm}$ rainfall during the growing season is needed for optimal growth of hemp. Other scientists underlined that even $500 \mathrm{~mm}$ of rain, dropped out during the vegetation period, is not enough for cannabis. Most of water is consumed in the period from bud formation till the end of flowering (50-70\% of total growing season precipitation) [7-9].

Stinging nettle (Urtica dioica L.) is the new fibrous plant in Lithuania; this plant has a lot of exclusive features. Even in the $17^{\text {th }}$ century European doctors stated that fibrous nettle has not only styptic properties, but it is also destroying pathogenic microbes and it is a wound healing plant. Stinging nettle leaves have a lot of vitamins. It is up to $0.6 \%$ of vitamin C, $50 \mathrm{mg} \%$ carotene (provitamin A). One kilogram of leaves has about 400 units of biological activity vitamin K. However, the leaves contain protein, sugar, starch, tanning materials, organic acids, chlorophyll, sitosterino, gum, iron salts, and so on. Some scientists state that during the first year of growth nettle proper crop yields will not form because nettle does not reach the required crop density and fiber content. Literature states that on productive fiber nettle yielding clones obtained per hectare of about 4 tons of dry plant with about 20-25\% of fiber yield [4]. Fibrous nettle and the residues of these plants should also be used as a stock material for biofuel production [10].

The aim of the research work is to investigate fibrous hemp and fibrous nettle preparation for fuel and to determine the qualitative indicators of the produced pellets.

\section{Materials and methods}

Moisture of pellets. Moisture of pellets is determined in chemical laboratories according to standard methodology. For determination of moisture, 3 samples $100 \mathrm{~g}$ each are taken. In the laboratory, relation of water in the sample with sample mass is determined, i.e. moisture of pellets is determined and calculated; average meaning of 3 samples is written down with error [9].

Biometrical parameters of pellets. Measurements and granulometric configuration of pellets. Measurements of the produced granules were determined. Diameter of the pellets is measured by sliding calipers ( $0.05 \mathrm{~mm}$ exactness) in the centre of granules. Each test is repeated 5 times; average meanings of the pellet mass and their errors are calculated.

Granule mass is determined by weighing with $0.001 \mathrm{~g}$ exactness. Average mass meanings of the measured 7 sort granules, 3 various size fractions are calculated, and they are written down with error.

While knowing the mass of a granule $m_{g r}$ (exactness of weight indices is $0.01 \mathrm{~g}$ ), density of granule mass $\rho_{g r}$ is calculated:

$$
\rho_{g r}=\frac{m_{g r}}{V_{g r}},
$$

where $\rho_{g r}$ - granule mass density $\mathrm{kg} \cdot \mathrm{m}^{-3}$.

The moisture of granules, density of dry material (DM) of each sort of fibrous hemp and fibrous nettle and data spread reliable interval (error) are calculated [9].

Granulometric configuration. Pellet granulometric (fractional) configuration was determined using a special sieve shaker Retsch AS200 and a set of $200 \mathrm{~mm}$ diameter sieves. Sieves with round holes are placed one on another (in succession starting from the upper sieve): $2 \mathrm{~mm} ; 1 \mathrm{~mm}, 0.63 \mathrm{~mm}$; $0.5 \mathrm{~mm} ; 0.25 \mathrm{~mm}$ and less than $0.25 \mathrm{~mm}$.

Pellet resistance to compression. When analysing resistance to compression of pellets of fibrous hemp and fibrous nettle, INSTRON testing equipment was used. The equipment is stored in the Aleksandras Stulginskis University, Institute of Agriculture Engineering and Safety (Fig. 2). During the tests, the pellets were put on a horizontal surface (table), and the pellets were affected by vertical load. 


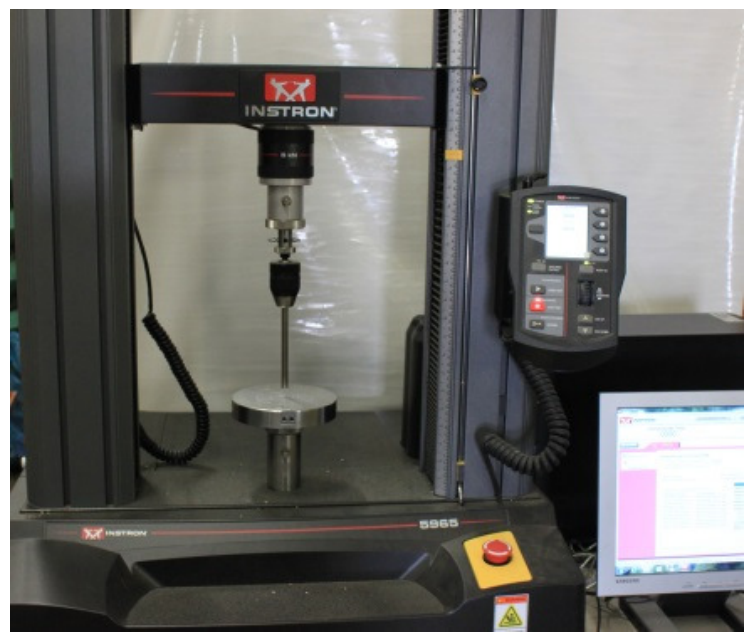

Fig. 1. Research equipment of material characteristics Instron 5960

The results of the test were registered every 0.1 second till all pellets dissociate under the force. The INSTRON equipment draws the Young's modulus characterising the pellet resistance. Tests are repeated 5 times with every sort of pellets. Measuring error is $0.02 \%$.

Having performed the experimental research, the received research data are processed by statisticmathematical methods. During data processing, average meanings and their reliability intervals are calculated; the limit of the essential difference under $95 \%$ of probability is evaluated.

\section{Results and discussion}

Fractional composition of fibrous hemp and fibrous nettle mill was determined with a sieve shaker Retsch AS200. The test was repeated 3 times with each fraction. The data are presented in Fig. 2-5.

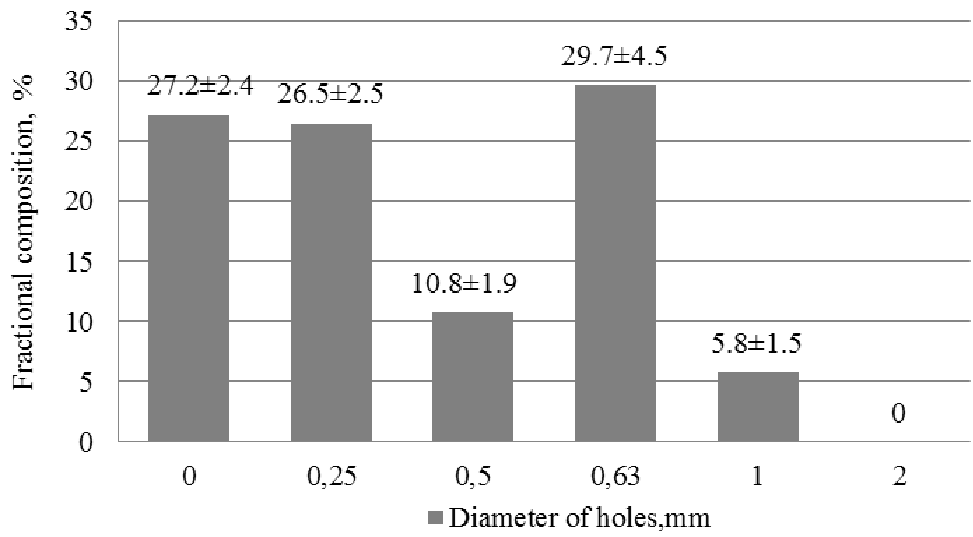

Fig. 2. Fractional composition of fibrous hemp USO 31

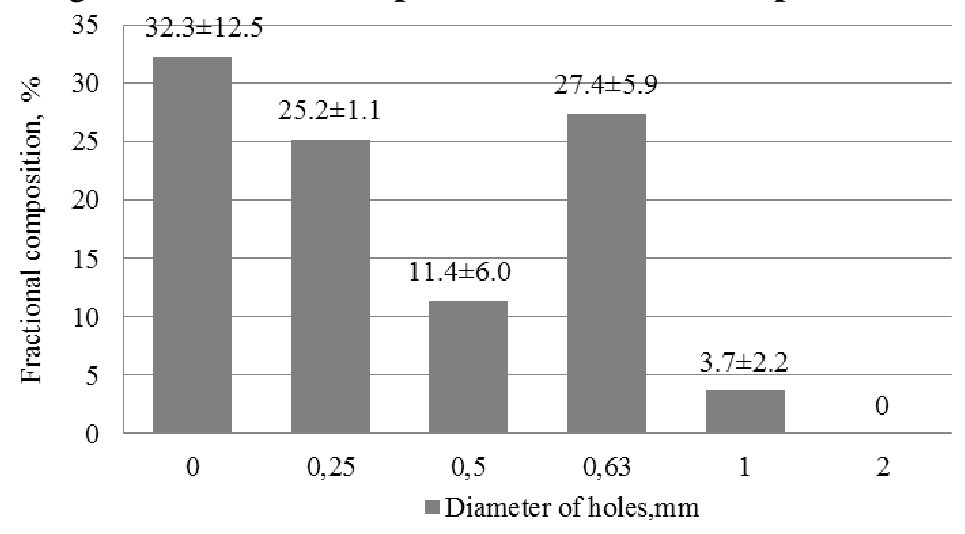

Fig. 3. Fractional composition of fibrous hemp Felina 32 


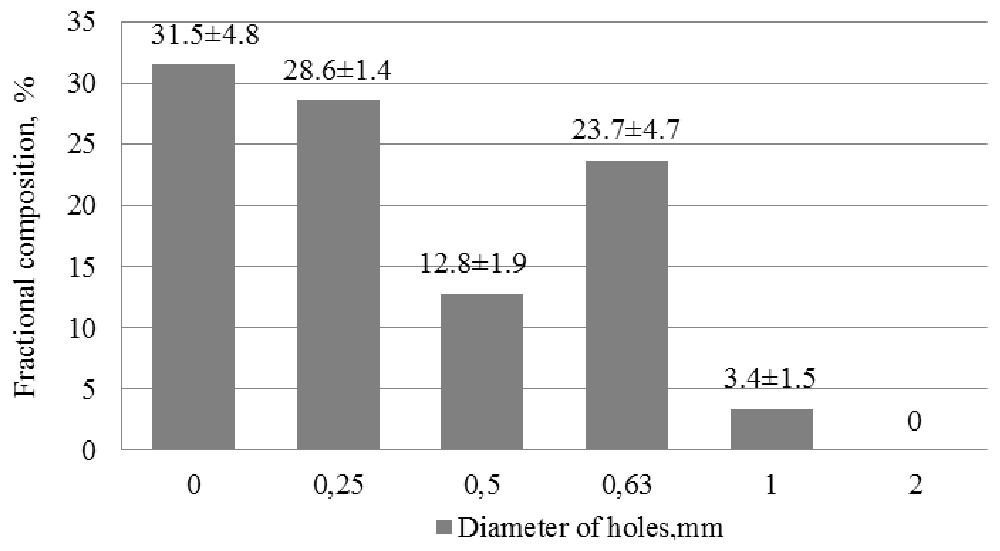

Fig. 4. Fractional composition of fibrous hemp Finola

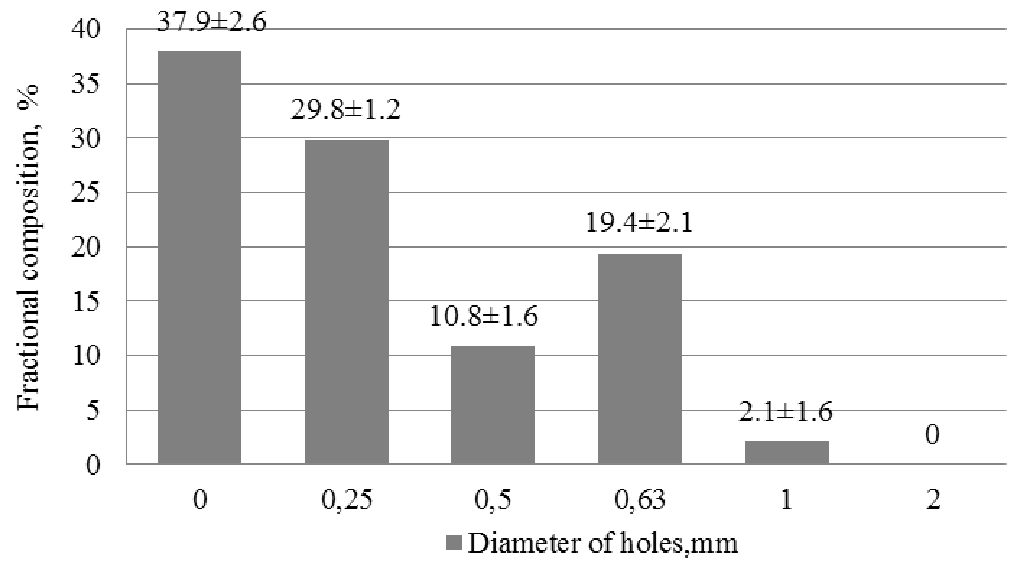

Fig. 5. Fractional composition of fibrous nettle

Having evaluated the fraction composition of the mill, we can see that big amount of mill fraction was on $0.63 \mathrm{~mm}$ sieves (reached $29.7 \pm 4.5 \%$ ), but too big amount of dust was found - from $27.2 \pm 2.4 \%$ to $37.9 \pm 2.46$. There was no fraction on a sieve with holes $2 \mathrm{~mm}$ diameter.

Determination of biometrical parameters of pellets. The analysed and determined biometrical parameters of granulated fibrous hemp and fibrous nettle pellets, the moisture content and density, are presented in Table 1.

Table 1

Biometrical parameters of granulated fibrous hemp and fibrous nettle pellets

\begin{tabular}{|c|c|c|}
\hline $\begin{array}{c}\text { Species of granulated } \\
\text { fertilizers }\end{array}$ & Moisture content, $\%$ & Pellet density, $\mathbf{~ k g} \cdot \mathbf{m}^{-\mathbf{3}}$ \\
\hline Finola & 7.30 & $\begin{array}{c}1286.2 \pm 17.0 \\
1192.3 \pm 17.0 \mathrm{DM}\end{array}$ \\
\hline Felina 32 & 9.98 & $\begin{array}{c}979.1 \pm 58.6 \\
899.3 \pm 58.6 \mathrm{DM}\end{array}$ \\
\hline USO 31 & 8.87 & $\begin{array}{c}1285.7 \pm 35.6 \\
1171.7 \pm 35.6 \mathrm{DM}\end{array}$ \\
\hline Fibrous nettle & 8.95 & $\begin{array}{c}1221.6 \pm 32.7 \\
1112.3 \pm 32.7 \mathrm{DM}\end{array}$ \\
\hline
\end{tabular}

The moisture content of the pellets varied from 7.30 to $9.98 \%$, and the biggest density was of fibrous hemp Finola $-1192.3 \pm 17.0 \mathrm{~kg} \cdot \mathrm{m}^{-3} \mathrm{DM}$.

In the Lithuanian Energy Institute, the fibrous hemp calorific value was determined: USO 31 17.38 MJ $\cdot \mathrm{kg}^{-1}$, Felina $32-17.37 \mathrm{MJ} \cdot \mathrm{kg}^{-1}$, Finola $-17.44 \mathrm{MJ} \cdot \mathrm{kg}^{-1}$ and fibrous nettle $-16.93 \mathrm{MJ} \cdot \mathrm{kg}^{-1}$. Ash content of fibrous hemp was determined: USO $31-3.89 \%$, Felina $32-3.60 \%$, Finola $-3.30 \%$ and fibrous nettle $6.57 \%$. 
Research on pellet resistance to compression. Resistance to compression is an important parameter for pellets of fibrous hemp and fibrous nettle. It is very important for transportation and storage of pellets. Having performed the research of the resistance to compression of three sorts of pellets of fibrous hemp and one sort of fibrous nettle, we received the results that are presented in Fig. 6-9.

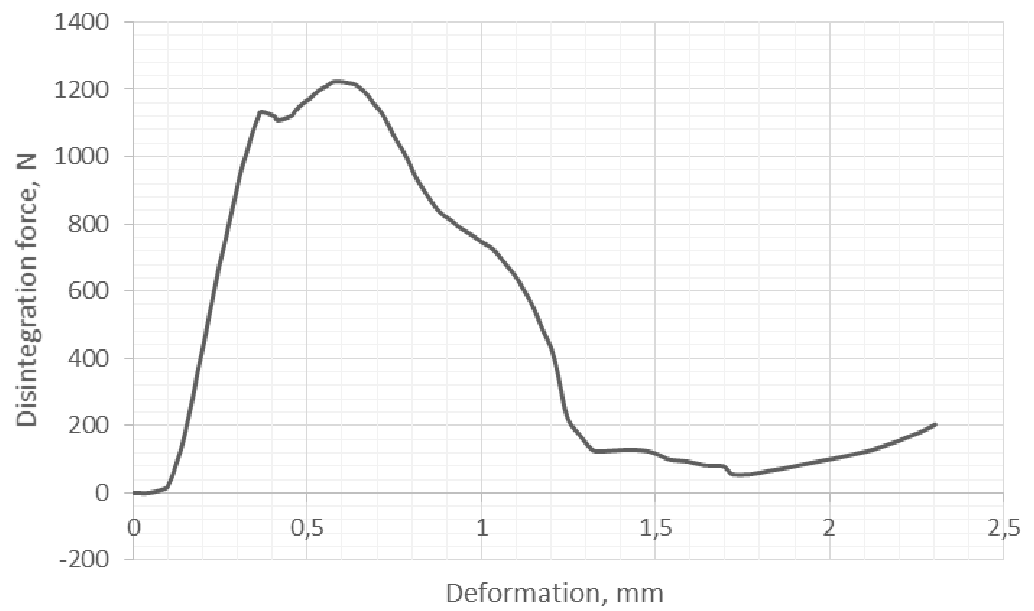

Fig. 6. Deformation (mm) and disintegration force (N) of fibrous hemp USO 31

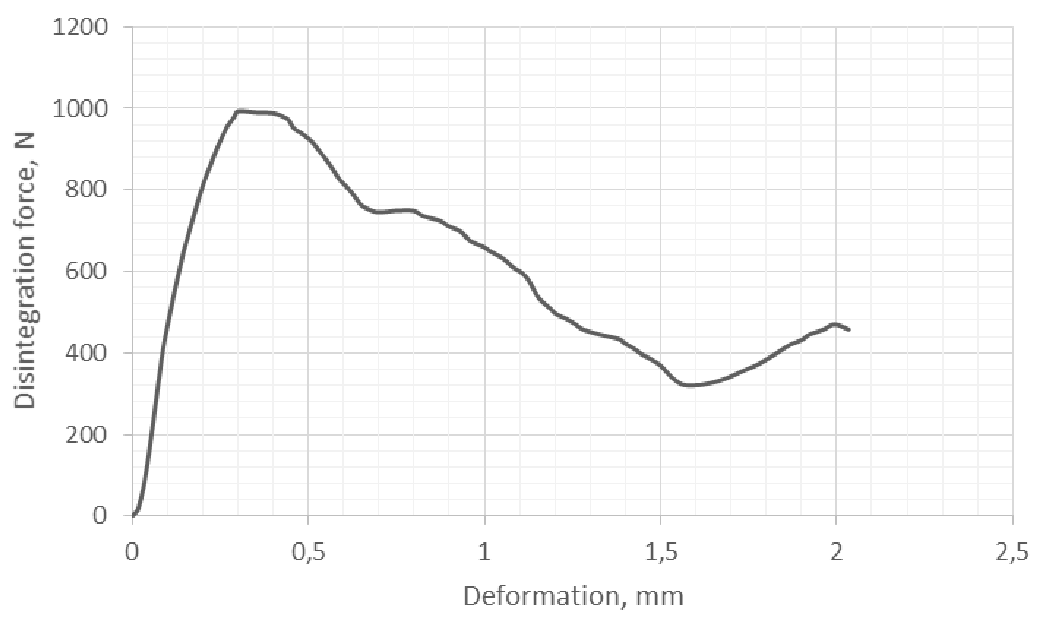

Fig. 7. Deformation (mm) and disintegration force (N) of fibrous hemp Felina 32

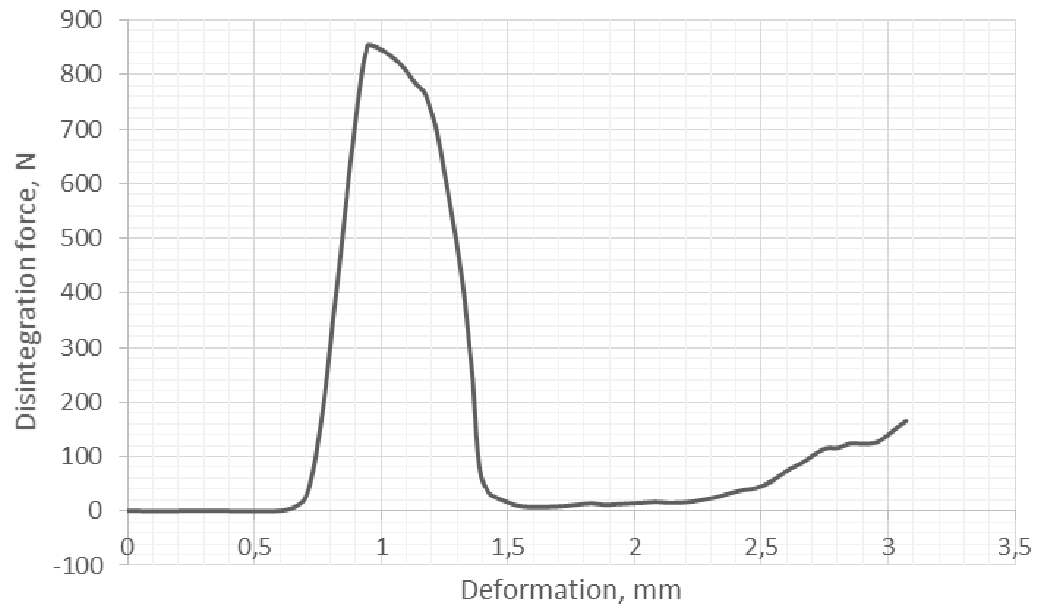

Fig. 8 . Deformation $(\mathbf{m m})$ and disintegration force $(\mathbf{N})$ of fibrous hemp Finola 


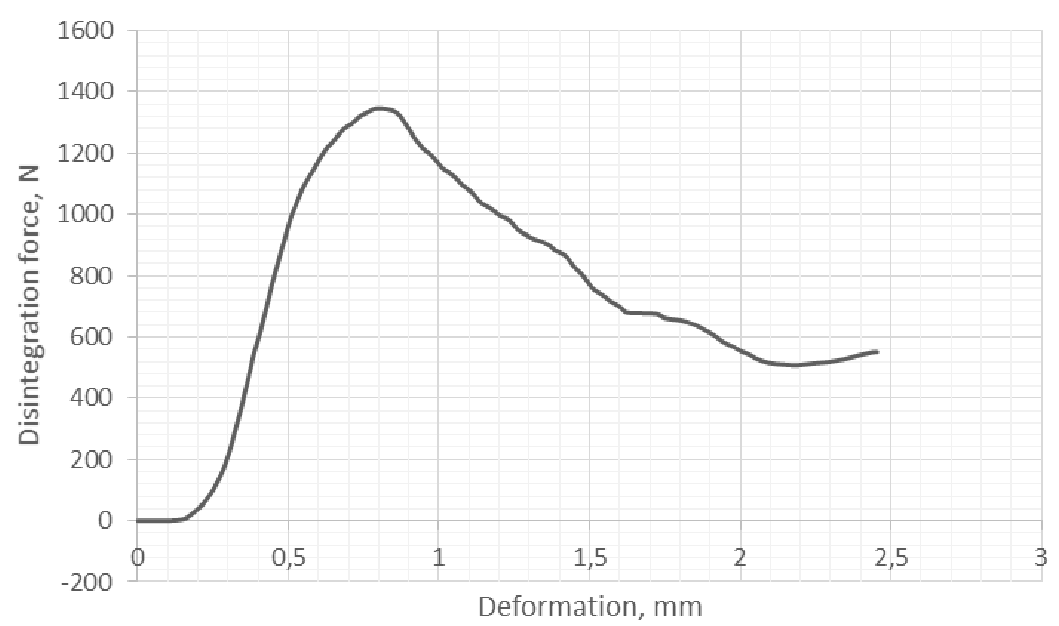

Fig. 9. Deformation ( $\mathbf{m m})$ and disintegration force $(\mathrm{N})$ of fibrous nettle

During the tests, the beginning of deformation of the pellets of plants (characteristic to that sort) and the force, under which a pellet is disintegrated, were determined.

Analysing the deformation curve (Fig. 6) of granulated USO 31, it may be seen that a pellet started deformation under the force of $10 \mathrm{~N}$, and under the force of $1223.12 \mathrm{~N}$ it disintegrated totally. Having evaluated the force and its change and the moisture of granules $(8.87 \%)$, it may be stated that these pellets are very resistant to static force and it is comfortable to transport and mechanically spread them.

Analysing the deformation curve (Fig. 7) of fibrous hemp Felina 32, it may be seen that granules started to deform quickly under the force of $0.9 \mathrm{~N}$, and under the force of $993.25 \mathrm{~N}$ they deformed. Having evaluated the force and its change and low moisture of granules $(9.98 \%)$, it may be stated that these pellets are sufficiently resistant to static force and they disintegrate rather quickly.

For fibrous hemp Finola we received the deformation curve (Fig. 8). It may be seen that the pellet started to deform under the force of $1.0 \mathrm{~N}$, and, under the force of $854.19 \mathrm{~N}$, it deformed and disintegrated. Having evaluated the force and its change and low moisture of pellets (7.3\%), it may be stated that these pellets are also not sufficiently resistant to static force and disintegrate quickly. Fibrous nettle pellets disintegrate under $1345.94 \mathrm{~N}$ force.

For the applicability of pellets for energy purposes it is also important to present the information about the elemental and chemical composition of pellets, as well information about the ash melting temperature and chlorine amount in pellets. Preliminary investigations were fulfilled and the elemental and chemical composition and main features of the tested pellets while burning them were set out.

The determined elemental composition of the investigated fibrous plants show, that the $\mathrm{C}$ (carbon) content was the biggest and reached 45.5-48.0 \%, $\mathrm{H}$ (hydrogen) content varied from 5.7 to $5.9 \%$, $\mathrm{N}$ (nitrogen) content varied from 0.6 to $1.2 \%$, and other chemical composition of $\mathrm{S}$ (sulphur) and $\mathrm{Cl}$ (chlorine) was small in volume (varied from 0.01 to $0.5 \%$ ). The ash content varied from 3.6 to $6.6 \%$ and the average calorific value when burning of all investigated sorts of fibrous plants was relatively high and varied from 17.1 to $17.6 \mathrm{MJ} \cdot \mathrm{kg}^{-1}$. For detailed presentation and publication of these research results another separate manuscript will be prepared.

\section{Conclusions}

1. The mill fractional composition of fibrous hemp and fibrous nettle was determined. The biggest amount accumulated dust shape: USO $31-27.2 \pm 2.4 \%$, Felina $32-32.3 \pm 12.5 \%$, Finola $31.5 \pm 4.8 \%$ and fibrous nettle $-37.9 \pm 2.6 \%$.

2. The plant pellet quality indicators were determined: humidity, density, ash content and calorific value. The calorific value of the pellets of fibrous plants varied from $16.93 \mathrm{MJ} \cdot \mathrm{kg}^{-1}$ to $17.45 \mathrm{MJ} \cdot \mathrm{kg}^{-1}$; humidity varied from 7.30 to $9.98 \%$; density ranged from $899.3 \pm 58.6 \mathrm{~kg} \cdot \mathrm{m}^{-3}$ to $1286.2 \pm 17.0 \mathrm{~kg} \cdot \mathrm{m}^{-3}$ and the ash content varied from $3.30 \%$ to $6.57 \%$. 
3. After investigation of the mill fraction composition it was determined that big amount of mill fraction was on $0.63 \mathrm{~mm}$ sieves (to $29.7 \%$ ), but too big amount of dust was found (27.2-37.9\%).

4. Using the equipment INSTRON 5960 the plant pellet compressive strength was determined. Fibrous hemp USO 31 had the biggest strength (pressing force of pellet degradation) of all fibrous hemp plants - 1223.21 N, Felina $32-1053.39$ N, Finola - 854.19 N. Fibrous nettle pellets were very strong and their pressing force of degradation reached $1345.94 \mathrm{~N}$.

5. Preliminary investigations were fulfilled and the elemental and chemical composition and main features of the tested pellets while burning them were set out.

\section{References}

1. Raslavičius L., Kučinskas V., Jasinskas A. The prospects of energy forestry and agro-residues in the Lithuania's domestic energy supply. Renewable and Sustainable Energy Reviews, vol. 22, 2013, pp. 419-431.

2. Vares V., Kask U, Muiste P., Pihu T., Soosaar S. Biofuels User's manual. Vilnius, 2007, 188 p. (In Lithuanian).

3. Cannabis helvetica. Machine a recolter le chanvre. [online] [12.04.2015]. Available at: http://www.canapa-info.ch/info/fr/Machine-a-recolter-le-chanvre.html.

4. Jasinskas A., Zvicevičius E. Biomass production engineering. Educational book for higher education. Akademija, 2008, 98 p. (in Lithuanian).

5. Harvesting technologies for industrial hemp. [online] [04.12.2015]. Available at: http://www. saskflax.com/documents/presentations/14B_Bednar.pdf.

6. Nebel K., Kokhan A., Selcuk R., Pichert T. Textiles from fibre nettles. Production, Processing and Use of Natural Fibres. Potsdam-Bornim, 2002, pp. 77-78.

7. Burczyk H., Kowalski M., Plawuszewski M. Trends and methods in hemp breeding in Poland. Journal of natural fibres, vol. 2 (1), 2005, pp. 25-33.

8. Butènaitè L., Jonaitienė V., Stanys S., Jankauskienè Z., Gruzdevienė E. Fibrous plant growing possibilities and prospects of Lithuania. Product Design and Technology: Proceedings of the Conference. KTU, Technologija, 2012, pp. 234-237 (In Lithuanian).

9. Bocsa I., Karus M. The cultivation of hemp: botany, varieties, cultivation and harvesting. Sebastopol, Canada: Hemptech, 1998, 186 p.

10. Streikus D., Jasinskas A., Arak M., Jotautienė E., Mieldažys R., Čekanauskas S., Jankauskienė Z. Investigations of fibre plants preparation and utilization of solid biofuels. Agronomy Research, vol. 14 (1), 2016, pp. 259-268. 